\title{
LA SOBERANÍA EN VITORIA EN EL CONTEXTO DEL NACIMIENTO DEL ESTADO MODERNO: ALGUNAS CONSIDERACIONES SOBRE EL DE POTESTATE CIVILI DE VITORIA*
}

\author{
Leopoldo José Prieto López \\ Universidad Francisco de Vitoria \\ lprieto7@gmail.com
}

RESUMEN. El artículo estudia algunas de las ideas políticas fundamentales presentes en el origen del Estado moderno, y especialmente la noción de soberanía política, que, inspirada tanto en la maiestas del Derecho romano imperial como en la interpretación averroísta de la idea aristotélica de comunidad perfecta, es recibida por Francisco DE VITORIA en el De potestate civili. VITORIA caracteriza la soberanía con las notas de supremacía en la actividad interna del Estado e independencia en relación con los demás Estados.

Palabras clave: soberanía, Estado, Iglesia, conciliarismo, Derecho romano imperial, averroísmo político, Marsilio de PADUA, Guillermo dE OCKHAM, Francisco DE VITORIA.

\section{The Sovereignty in Vitoria in the Birth of the Modern State: some Considerations on the De potestate civili of Vitoria}

ABSTRACT. The article studies some of the most important political ideas present in the origins of the modern State, especially the notion of political sovereignty, which, borne and developed in the maiestas of the imperial roman law and in the averroistic interpretation of the aristotelian idea of the perfect community, is accepted and developed by Francisco DE VITORIA in the De potestate civili. VITORIA characterizes sovereignty with the features of supremacy in the domestic activity of the State and independence with regard to other States.

Keywords: sovereignty, State, Church, conciliarism, imperial roman law, political averroism, Marsilius OF PADUA, William OF OCKHAM, Francisco DE VITORIA.

* Fecha de recepción: 23 de enero de 2016. Fecha de aceptación: 20 de enero de 2017.

El artículo aquí presentado se corresponde en parte con la ponencia La noción de soberanía política en Vitoria y Suárez en el contexto del nacimiento del Estado moderno. Algunas consideraciones sobre el De potestate civili de Vitoria y la Defensio fidei de Suárez, presentada en el «I Seminario del Instituto de Historia-CSIC y la Universidad Francisco de Vitoria», titulado «Francisco de Vitoria (1483-1546), su tiempo y su proyección», el 2 de diciembre de 2015 en el Centro de Ciencias humanas y sociales del CSIC. 


\section{ALGUNAS IDEAS SOBRE EL ORIGEN DEL ESTADO MODERNO}

A ntes de abordar el estudio del De potestate civili de Francisco DE VITORIA y de su recepción de la noción de soberanía política, presentamos preliminarmente algunos hechos e ideas que poco a poco han ido surgiendo en la filosofía política de la Baja Edad Media y que consideramos fundamentales tanto en relación con el origen del Estado moderno como con el desarrollo de la noción de soberanía política, tal como aparece esta idea, ya en el siglo XVI, en la obra de VITORIA. Los hechos e ideas a los que nos referimos son: algunos conceptos nuevos en el campo del pensamiento político; el nacimiento del espíritu nacional y laico ${ }^{1}$; la recepción del Derecho romano y del aristotelismo político; dos disputas paradigmáticas en el siglo XIV entre príncipes y papas; el surgimiento del conciliarismo como una nueva eclesiología de signo democrático.

La Baja Edad Media es, en efecto, de crucial importancia para comprender el espíritu de la filosofía política moderna. Como ha dicho A. BLACK, el periodo comprendido entre 1250 y 1450 es de capital importancia para los valores y la política del mundo moderno, porque en él fueron formuladas por primera vez en su forma moderna ideas tales como «la soberanía del Estado, la separación de Iglesia y Estado, la representación y el origen popular del gobierno»².

\subsection{Nuevos conceptos en el campo de las ideas políticas}

Si el Medievo, desde el punto de vista político, fue el tiempo del universalismo político, del objetivismo y del clericalismo, la Época Moderna se caracteriza por el surgimiento de la subjetividad (expresada políticamente en el auge del nacionalismo en la forja de los Estados modernos), la fragmentación de un orden político universal y el nacimiento del espíritu laico ${ }^{3}$.

Naturalmente, la transición de la Edad Media a la Moderna se realiza lenta y gradualmente en un proceso histórico que dura varios siglos, más o menos desde el siglo XIV al siglo XVII. Por eso, para comprender mejor algunas de las ideas fundamentales que dominan el horizonte de la filosofía política de la Modernidad, a la que pertenece de pleno derecho ya Francisco DE VITORIA, es necesario retroceder hasta el siglo XIV.

Pues bien, en este proceso histórico que va del siglo XIV al XVII se advierte, ante todo, la aparición de dos grandes novedades en el campo de las ideas políticas: $a$ ) una nueva concepción del poder político, a saber, la soberanía, acompañada de una natural tendencia hacia el absolutismo político ${ }^{4}$, y $b$ ) un modelo de relación entre la Iglesia y el

\footnotetext{
1 Se toma la expresión laico en el sentido de no clerical, no ciertamente en el de aconfesional.

2 A. Black, El pensamiento político en Europa (1250-1450), Madrid, Akal, 2003, ix. Cfr. M. J. WiLKs, The problem of sovereignty in later Middle Ages, Cambridge, Cambridge University Press, 1963, especialmente el capítulo «The Sovereign Prince», 151-183.

3 Cfr. J. LoRTZ, Historia de la Iglesia, II, Madrid, Ediciones Cristiandad, 2008, 5.

4 A propósito de la relación entre Estado moderno, soberanía y absolutismo, cfr. P. TOUBERT, «Eglise et Etat au XI ${ }^{\mathrm{e}}$ siècle: la signification du moment grégorien por la genèse de l'État moderne», en J. Ph. GENET y
} 
nuevo actor político que es el Estado, que, sugerido por el naciente laicismo inspirado en el Derecho romano, es corroborado por ciertas ideas eclesiológicas que favorecen tanto la tendencia a la formación de las iglesias nacionales (anglicanismo, galicanismo, etc.) como una nueva interpretación de la naturaleza de la potestad eclesiástica realizada por el conciliarismo.

Como no podía ser de otro modo, encontramos estas dos nuevas ideas en el pensamiento de Francisco DE VITORIA (1486-1546), especialmente en las siguientes obras: De potestate civili (1528), De potestate Ecclesiae prior (1532), De potestate Ecclesiae posterior (1533) y De potestate Papae et Concilii (1534). La noción de soberanía, como veremos más adelante, aunque presente solo de un modo implícito antes de su formulación canónica por BODIN, se halla en la concepción de VITORIA del Estado (o de la república, como lo suele llamar) como una sociedad perfecta. En cuanto tal, como veremos, el Estado no puede ser más que una comunidad política en la que el príncipe ejerce un poder supremo (desde el punto de vista interno) e independiente (desde el punto de vista externo). A su vez, las cuestiones relativas a la delimitación y armonización del poder civil y eclesiástico, y dentro de este a la delimitación del poder del papa y del concilio, revisten una notabilísima importancia en su obra. En efecto, las relecciones De potestate Ecclesiae (prior y posterior) y De potestate Papae et Concilii manifiestan el vivo interés que VITORIA siente por esta materia. La formación recibida por VITORIA en una Francia fuertemente inclinada al conciliarismo y galicanismo ya desde

B. VINCENT, Etat et Eglise dans la genèse de l'Etat moderne, Madrid, Casa de Velázquez, 1986, 9-22. Según TOUBERT es necesario retroceder hasta la reforma gregoriana del siglo XI para comprender el origen de algunas ideas importantes sobre la relación de la Iglesia y Estado tal como se desarrollarán posteriormente en la Época Moderna. En su opinión, en el contexto de la reforma gregoriana el papado hizo suyos no pocos elementos del modelo político-imperial, como ya indicaron en su momento H. W. KLAUWITZ (Reformpapstum und Kardinalkolleg, Darmstadt, Wissenschaftliche Buchgesellschaft, 1957) y G. ALBERIGO (Cardinalato e collegialità: Studi sull'ecclesiologia tra l'XI e il XIV secolo, Firenze, Vallecchi, 1969), tales como una administración financiera centralizada de la Iglesia, una cancillería pontificia y, sobre todo, la creación de un espacio geográfico de poder en el centro de Italia constituido como base territorial de su acción de gobierno. Todas estas realizaciones hicieron posible la concepción de una Christianitas, promovida por la reforma gregoriana, que desembocó en el siglo XII en la idea de institutio, cargada de implicaciones políticas y eclesiásticas, que anticipa la idea de soberanía que tiempo después reclamará para sí el naciente Estado moderno. Así, «en el cisma irreparable que se da entre Regnum y Sacerdotium, la concurrencia de los dos protagonistas a un poder supremo [sobre la Christianitas] ha permitido la elaboración, por vía de intercambios y transferencias de prerrogativas, de una ideología bastante uniforme de la soberanía» (21). Hace tiempo que P. E. SCHRAmm puso de manifiesto las convergencias ideológicas en el ámbito de los símbolos de Estado, mostrando por medio de qué transferencias de prerrogativas y derechos honoríficos el Regnum ha querido manifestarse como Sacerdotium, e inversamente, el Sacerdotium ha querido convertirse en Regnum, responsable de un proyecto histórico que va más allá del destino de los regna individuales [cfr. P. E. ScHRAMm, «Sacerdotium und Regnum im Austausch ihrer Vorrechte: eine Skizze der Entwicklung zur Beleuchtung des Dictatus Papae Gregors VII», en Studi gregoriani, 2 (1947), 403-457]. Por su parte, E. KANTOROwICZ prolongó la investigación de SCHRAmm focalizando en el final de la Edad Media y el inicio de la Edad Moderna esta dinámica de transferencias entre papas coronados y reyes mitrados [cfr. E. KANTOROWICZ, «Mysteries of State. An absolutist Concept and its late Mediaeval Origins», en Harvard Theological Review, 48 (1955) 65-91]. En palabras de KANTOROWICZ, es claro que «bajo un Papa convertido en princeps et verus imperator el aparato jerárquico de la iglesia romana [...] manifestaba la tendencia a convertirse en el prototipo perfecto de una monarquía absoluta y racional fundada sobre una base mística, a la vez que el Estado tenía cada vez más la tendencia a convertirse en una cuasi-iglesia, o de otra manera, en una monarquía mística fundada sobre una base racional» (79). De este modo, KANTOROWICZ llamaba la atención sobre determinados conceptos políticos, en virtud de los cuales los misterios de la Iglesia, los arcana Ecclesiae, eran transferidos al Estado, que elaboró así sus propios misterios del Estado, los nuevos arcana imperii seculares, que se encuentran en la raíz misma del absolutismo moderno. 
los siglos XIV y XV [con D’AILLY (1350-1420) y GERSON (1363-1429), ambos rectores de la Universidad de París, el alma mater de VITORIA], así como el fuerte influjo de sus maestros MAIR (1467-1550) y ALMAIN (1480-1515), los principales sostenedores del conciliarismo en la Universidad de París en el siglo XVI, explican la presencia en el dominico español de algunas ideas que pueden denotar un moderado conciliarismo ${ }^{5}$.

\subsection{Estado moderno, sentimiento nacional y esprit lä̈que}

El ideal de una Cristiandad que unía a todos los pueblos cristianos bajo la autoridad temporal del emperador y la espiritual del romano pontífice, que parecía haberse logrado en el siglo XIII, se reveló ya desde inicios del siglo XIV un proyecto fracasado. Los dos poderes que unificaban la Europa cristiana, el imperio y el papado, comienzan a perder autoridad y prestigio. Se entabla entonces una pugna en la que resultarán vencedores el sentimiento nacional y el Estado moderno, que terminan ocupando las parcelas de poder que el imperio y el papado pierden progresivamente. Como ha expuesto lúcidamente LAGARDE, se asiste en esta época al nacimiento del espíritu laico,

5 Sobre un posible conciliarismo, de seguro moderado, de Francisco DE VITORIA, cfr. R. GARCía ViLLOSLADA, La universidad de París durante los estudios de Francisco de Vitoria O.P. (1507-1522), Romae, Apud aedes Universitatis Gregorianae, 1938, 157: «Lo verdaderamente extraño es que un dominico español como VITORIA, tan poderosamente influido por las doctrinas teológicas de Cayetano y Torquemada, los grandes adalides del Primado romano contra galicanos y conciliaristas, se exprese con tanta reserva y cercene lamentablemente la plenitudo potestatis del sucesor de san Pedro frente a la autoridad de los Concilios». Más adelante, prosigue GarCía Villoslada, «Francisco DE Vitoria [...] se contagió un poco — fuerza es decirlo- de las ideas conciliaristas que se respiraban en la atmósfera universitaria y política de Francia» (172), como resultaría de la afirmación del De potestate Ecclesiae posterior, n. 6, donde si bien no defiende la superioridad del concilio sobre el papa, tampoco se atreve a defender lo contrario. Dice en efecto, VITORIA, a propósito de cuál de las dos potestades es superior en la Iglesia, el concilio o el papa: «Responderé en primer lugar que ahora no intento discutir de aquella odiosa comparación entre el Papa y el Concilio», para rematar inmediatamente después que «se puede sostener que es mayor la potestad del Concilio que la del Papa» (172). También J. GoÑI ha sostenido la tesis de un conciliarismo moderado de Francisco DE VITORIA. Afirma este autor: «En Francisco DE VITORIA, formado en la universidad de París, uno de los últimos reductos del conciliarismo, se detectan algunos resabios de conciliarismo sin ser personalmente conciliarista» [J. GOÑI GAZTAMBIDE, «El conciliarismo en España», en Scripta theologica, 10/3 (1978), 893-928, 924]. En concreto, prosigue GoÑI, «el concilio puede convocarse y reunirse contra la voluntad del papa para oponerse a él y contrarrestar su insolencia, si con mandatos insolentes y dispensas injustas causa grave daño a la Iglesia. La autoridad del papa puede ser limitada cuando existe una necesidad apremiante. ¿Por quién? Por el concilio» (924). De manera que, aunque VITORIA quiso oponerse al conciliarismo, «no logró superar, sin embargo, totalmente el error y en última instancia sometió el papa al concilio en determinados casos excepcionales» (925). En este mismo sentido, «en sus lecturas sobre la Secunda Secundae de 1526-1527 encontramos esta chocante frase: "Si el papa quisiese definir por sí mismo una proposición de fe sin un concilio y sin examinar la Escritura, podría errar" [...] El concilio es así el medio supremo de hallar la verdad, necesario en los casos difíciles» (925). Por el contrario, la tesis sobre un posible conciliarismo moderado de VITORIA fue atacada tanto por T. URDÁNOZ como por el carmelita J. DE JESÚs MARíA. Dice, en efecto, URDÁNOZ: «En ninguna de las dos relecciones [De Potestate Ecclesiae, prior y posterior, y De potestate concilii et Papae] ha querido resolver directamente la cuestión central de la superioridad entre ambas potestades del Papa y del concilio, por lo que no puede esperarse de él una refutación completa y sistemática del conciliarismo. Esa cuestión básica ha sido soslayada en esta relección por nuestro teólogo, que la llama odiosa comparación [...]. Más bien adopta en torno a ella una actitud de imparcial y aparente indecisión [...] Pero, en realidad, VITORIA rechaza de plano en ambas relecciones toda la teología conciliarista. Solo que su verdadero propósito es hacer una labor teológica constructiva y no simplemente de negativa repulsa de los excesos conciliaristas» (T. URDÁNOZ, Obras de Francisco de Vitoria, Madrid, BAC, 1960, 335). URDÁNOZ recurre a la autoridad de J. DE JESÚS MARÍA, en cuyo artículo «¿Francisco DE VITORIA conciliarista?», «se sostiene con decisión y se demuestra bien claramente que VITORIA rechaza abiertamente la teología conciliarista» (335). Cfr. J. DE JESÚS MARÍA, «¿Francisco DE VITORIA conciliarista?», en Ephemerides Carmeliticae, 1 (1947), 103-148. 
que da origen al Estado moderno ${ }^{6}$. El historiador del pensamiento medieval F. VAN STEENBERGHEN, preguntándose qué debe entenderse por espíritu laico, responde al respecto: «La expresión significa en primer lugar, de una manera general, la reacción de los simples fieles contra la hegemonía del clero en el seno de la Iglesia, o el esfuerzo de emancipación del laicado [...]. Pero en un sentido más preciso, el espíritu laico se refiere a las luchas por el poder espiritual y el poder temporal entre la Iglesia y el Estado y en tal sentido designa la tendencia a reivindicar, en pugna con la Iglesia, la integridad de los derechos soberanos de las sociedades civiles» ${ }^{7}$. El espíritu laico rechaza la idea misma de Cristiandad y con ella, la pretensión del clero de influir en la vida social de Europa. Sentimiento nacional y espíritu laico van de la mano en las reivindicaciones contra el papado en la construcción del Estado moderno.

\subsection{El retorno a las fuentes antiguas: aristotelismo político y Derecho romano}

Las nuevas ideas y sentimientos políticos recurren a dos fuentes intelectuales procedentes de la Antigüedad clásica, cuya contribución será decisiva en la transformación del panorama jurídico-político en los albores de la Modernidad: la recepción del Derecho romano y el aristotelismo político, especialmente en su concepción averroísta. Paradójicamente, como en otros campos del saber, la evolución en la historia de las ideas políticas ha ido acompañada de un retorno a las fuentes antiguas. Así, en la lucha sostenida contra el papado y el imperio, el Estado y la monarquía modernos recurrieron a la inspiración que la Antigüedad clásica les ofrecía en dichas fuentes.

El Derecho romano era un arma eficaz para combatir la concepción feudal del poder político. A la atomización del poder político, característica del feudalismo, y a su igualmente característica confusión del ámbito del derecho privado con el derecho público, el Derecho romano oponía una idea clara y nítida del poder público, el imperium, y del Estado o res publica. El imperium era entendido como el poder pleno, indiviso y absoluto entregado a quien personifica y rige el Estado, el princeps. Tal poder pleno es la maiestas o soberanía. El Derecho romano, especialmente en época imperial, no admitía la doctrina, típicamente cristiano-medieval, de los límites del poder político. En este sentido había dicho UlPIANO: Quod principi placuit, legis habet vigorem ${ }^{8}$. Se entiende así que la ley emana de la voluntad del princeps. Así también en la Baja Edad Media y Renacimiento se usará frecuentemente la expresión conclusiva en leyes y decretos dictados por el rey de que «tal es el beneplácito del rey», «porque así plugo al rey», etc. El rey ahora se presenta como el princeps, el primero del Estado. En este mismo sentido, A. MARONGiU ha visto en el uso del título de Majestad, del que

\footnotetext{
${ }^{6}$ Cfr. G. De Lagarde, La naissance de l'esprit lä̈que au déclin du moyen âge, 5 vols., Louvain-Paris, Nauwelaerts, 1956-1963. La expresión espíritu laico la tomamos aquí exactamente en el mismo sentido que tiene en la obra de G. DE LAGARDE, no pretendiendo en modo alguno extrapolar su sentido anacrónicamente a cuestiones sobre la aconfesionalidad del Estado, que no tienen cabida en los autores de la Baja Edad Media e inicios de la Época Moderna. Cfr. supra, nota 1.

7 F. van STEENBERGHEN, recensión de G. DE LAGARDE, «La naissance de l'esprit laïque au déclin du moyen âge», I, en Revue philosophique de Louvain, 68 (1962), 688-691, 688. Trad. propia.

8 UlPIANO, Institutiones, I, D. 1,4,1. A propósito de la recepción y práctica en la monarquía española de estas ideas procedentes del Derecho romano, $c f r$. S. DE Dios, El poder del monarca en la obra de los juristas castellanos (1480-1680), Cuenca, Ediciones Universidad Castilla-La Mancha, 2014, 24 y ss.
} 
los monarcas modernos se apropian ahora resueltamente, un indicio inequívoco de lo que ha llamado el proceso de imperialización de la figura del rey, característico de las monarquías del Renacimiento ${ }^{9}$. Es indicativo a este respecto que la correspondencia dirigida a Carlos V, por ejemplo, de quien Francisco DE VITORIA era coetáneo, fuera frecuentemente encabezada con la fórmula «a la sacra, cesárea y católica Majestad» ${ }^{10}$.

A su vez, el aristotelismo político contribuía en esta misma dirección. Si el Estado era concebido como algo natural y racional, ¿qué necesidad tenía entonces de una justificación y una sanción sobrenatural? Más aún, si el Estado perseguía fines no simplemente materiales, sino también morales, como favorecer la virtud de sus miembros, y si los hombres tendían naturalmente hacia una forma de vida social autosuficiente, como era la sociedad perfecta, ¿por qué la vida política debía someterse a la jurisdicción espiritual de un poder exterior a ella misma como era la Iglesia, cuyos derechos se basaban en la verdad revelada y en la vida sobrenatural, instancias que excedían con mucho lo que la sociedad requería? Si estos problemas no habían incomodado a fines del siglo XIII a Tomás DE AQUINO ello se debía al ideal que dominaba su pensamiento: la armonía entre fe y razón, teología y filosofía. Pero precisamente era este ideal el que se estaba desvaneciendo a inicios del siglo XIV en otros pensadores, particularmente los pertenecientes a aquella corriente llamada aristotelismo averroísta o averroísmo latino (a la que Juan DE JANDÚN y Marsilio DE PADUA pertenecen de pleno derecho), cuyo pensamiento se caracterizaba por una neta separación de fe y razón, hasta llegar al extremo de sostener la teoría de la doble verdad ${ }^{11}$. En realidad, la relación entre Iglesia y Estado no era sino la aplicación al campo del derecho y la política del tema general de la relación entre fe y razón, que el averroísmo latino consideraba inexistente.

\subsection{Dos disputas tardomedievales en los albores de la Modernidad}

La transición de la política medieval a la moderna se expresa, además de en el surgimiento de nuevos conceptos y nuevas fuentes (paradójicamente antiguas), en dos

9 Cfr. A. Marongiu, Lo Stato moderno. Lezioni di storia delle istituzioni politiche, Roma, Edizioni Ricerche, 1967. No se olvide que esta es la época de ViTORIA.

10 Cfr. V. DE Cadenas, Carlos de Habsburgo en Yuste, Madrid, Hidalguía, 2000, 79-83. En el uso de estos títulos vemos un ejemplo concreto de la transferencia de prerrogativas y honores de la Iglesia (sacra y católica) al Estado (cesárea Majestad) referida antes. Cfr. supra, nota 4.

11 Cfr. P. Mandonnet, Siger de Brabant et l'averroïsme latin au XIII siècle, Louvain, Institut Supérieur de Philosophie de l'Université, 1911, 142-195, donde en particular se dice: «No hay que olvidar que el reino de Felipe el hermoso fue testigo de un renovado vigor del averroísmo en París. Juan DE JANDún y Marsilio DE PADUA, los defensores de las pretensiones reales, eran averroístas notorios» (188, nota 4). Trad. propia. Sobre la teoría de la doble verdad, $c f r$. N. ABBagnano, Storia della filosofía, I, $\$ 286$ (Sigieri: L'eternità del mondo e la doppia verità), 590-593. Cfr. también J. FERRATER MORA, voz «Verdad doble», en Diccionario de filosofía, III, Madrid, Alianza, 1990, 3408-3409; A. MAIER, «Das Prinzip der doppelten Wahrheiten», en A. MAIER, Metaphysische Hintergründe der spätscholastischen Naturphilosophie, Roma, Edizioni di storia e letteratura, 1955 , 3-44; T. DoDD, The Life and Thought of Siger of Brabant, Thirteenth-Century Parisian Philosopher: An Examination of His Views on the Relationship of Philosopby and Theology, Lewiston, Edwin Mellen Press, 1998. En un sentido general puede decirse que la teoría de la doble verdad, mantenida más o menos explícitamente por un cierto número de filósofos y teólogos medievales y renacentistas relacionados por lo general con el averroísmo (entre los que se cuentan especialmente Siger DE BRABANTE, Juan DE JANDÚn, Marsilio DE PADUA y Pietro POMPONAZZI), consiste en afirmar la existencia de un contraste entre la verdad filosófica y la verdad revelada, de manera que lo verdadero en filosofía puede no serlo en teología y viceversa. 
polémicas, que trascienden el carácter de meros hechos históricos y alcanzan el valor de símbolos de lo que está por venir. En efecto, dos polémicas, cronológicamente muy próximas entre sí, a inicios del siglo XIV, harán visible el espíritu del tiempo y de la nueva filosofía política. Se trata de las disputas entre dos príncipes y dos papas: Felipe IV de Francia, llamado el hermoso, con Bonifacio VIII, de un lado; y Luis IV de Baviera con Juan XXII, de otro. El motivo inmediato de las mismas no podía ser otro que el replanteamiento de la relación entre potestad temporal y espiritual en el contexto de las relaciones entre papado, imperio y los nacientes Estados modernos.

a) La polémica de Felipe el hermoso y sus caballeros en leyes y Bonifacio VIII simboliza el violento contraste que, a inicios del siglo XIV, se da entre la Edad Media, representada por el romano pontífice (que, en la bula Unam sanctam de 1302, seguía amparándose en los viejos principios del agustinismo político), y la Edad Moderna, que, personificada en Felipe IV de Francia, se levanta con aspiraciones laicas y absolutistas $^{12}$.

El elemento doctrinal más sobresaliente en esta disputa es la influencia del Derecho romano en la mentalidad de los legistas de la corte francesa (Pedro FLOTTE, Guillermo DE Nogaret, Pedro DubOIS, etc.). Con una lógica abstracta, tan distinta del pensamiento medieval, los legistas de Felipe el hermoso combatieron teóricamente la organización feudal y la constitución jerárquica de la sociedad, que reverenciaba al emperador y atendía las directrices del romano pontífice, fomentando en cambio, el absolutismo regio ${ }^{13}$. Por influjo de estos teóricos del Derecho, el rey se creyó investido de un poder absoluto, cual ley viviente de la nación, y, en calidad de tal, empezó a considerarse superior a toda autoridad humana, no tolerando a partir de entonces injerencia alguna o intromisión de la Iglesia en los asuntos temporales e, incluso, en los espirituales. Es el origen del galicanismo y de las distintas formas de predominio del poder político sobre el espiritual. Estos legistas modificaron profundamente la figura y la función del rey, proclamándolo soberano y princeps, monarca absoluto, o lo que es igual, absuelto o libre de todo vínculo y restricción. Atribuyeron también a este príncipe y rey soberano, como sabemos, la función de fuente y origen de la ley. Por otro lado, el interés del príncipe en los asuntos de la Iglesia situada en el territorio de su jurisdicción nacional (lo que recibe propiamente el nombre de regalismo) era una tentación difícil de vencer. Paradigma de este espíritu fue la asamblea del clero francés, reunida en Bourges por el rey Carlos VII, que promulgó la Pragmática Sanción de 1438, por la que se otorgaba al rey de Francia un amplio derecho de vigilancia sobre la Iglesia de Francia ${ }^{14}$. Así, absolutismo y regalismo nacen de un mismo espíritu.

12 Cfr. G. DE LAGARDE, La naissance de l'esprit läque, I, 1956, 208-210. Según LAGARDE la querella bonifaciana puede ser considerada justamente como «la introducción a la política religiosa de los tiempos modernos». En tal sentido, esta querella no solo abre las puertas al galicanismo, sino que tiene una dimensión más profunda, porque «los abogados del príncipe, expresan con rara fortuna, las reivindicaciones fundamentales del Estado moderno frente a la sociedad religiosa: soberanía sobre los bienes y las personas, ejercicio exclusivo de la justicia, autonomía absoluta de la legislación, control de la vida espiritual de la nación» (G. DE LAGARDE, La naissance de l'esprit laïque, I, 210). Trad. propia.

13 Cfr. R. García Villoslada, Historia de la Iglesia católica, II, Madrid, BAC, 1988, 571.

14 La Pragmática Sanción de Bourges proclamada por el rey Carlos VII de Francia, el día 7 de julio de 1438, con el acuerdo del clero francés reunido en Bourges exigía que un concilio general de la Iglesia, cuya autoridad se consideraba superior a la del papa, había de celebrarse cada diez años. Así, el rey de Francia se proclamaba protector de la fe en territorio francés. Esta ordenanza constituía de algún modo una alianza 
Desde el punto de vista internacional, estos legistas y juristas de la corte consideraban que el príncipe no estaba sujeto a ninguna autoridad superior, fuera política (el emperador) o religiosa (el papa). Consecuencia necesaria de ello debía ser el fin del universalismo político medieval con la consiguiente fragmentación de la Cristiandad y el inicio del nacimiento de los nuevos Estados nacionales. El Estado y en él el príncipe eran considerados ante todo soberanos, es decir, entidades políticas supremas, no sometidas, por tanto, a ninguna otra instancia superior. El emperador perdía el poder de coerción sobre los reyes y pasaba a ser un príncipe más. Al papa no se le reconocía potestad de intervención sino en aquellos asuntos de naturaleza estrictamente espiritual. Resultaba así que el príncipe era el gran vencedor en el reparto de poder al que se asiste en los albores de la Edad Moderna.

b) La segunda polémica tiene lugar también en el siglo XIV, a pocos años de distancia de la anterior, esta vez entre Luis IV de Baviera, elegido emperador por los electores alemanes (de cuyo lado se pondrán Marsilio DE PADUA y Guillermo DE OCKHAM), y el papa Juan XXII. En la doctrina de Marsilio DE PADUA el elemento doctrinal prevalente es el aristotelismo averroísta; en la de OСКHAM, en cambio, una eclesiología conciliarista, reforzada por una metafísica del individuo, alimentadas ambas por la cuestión de fondo de la reivindicación franciscana de la pobreza, el rechazo del fasto de la corte papal de Aviñón y la revuelta de los fratricelli y espirituales contra un papado prisionero del monarca francés en la que entonces se llamó la cautividad babilónica.

Escrito contra el perturbador de la paz, Juan XXII, el Defensor pacis de Marsilio DE PADUA representa una poderosa máquina de guerra política e ideológica: una obra en la que se exponían las ideas conciliaristas más radicales contra la autoridad del pontífice y contra la constitución jerárquica de la Iglesia, exaltando hasta límites sorprendentes, propios ya del absolutismo, la potestad del príncipe secular ${ }^{15}$. La doctrina del Defensor pacis es la creación más notable del pensamiento político tardomedieval. Aparece en ella claramente, por primera vez, a qué extremas consecuencias podía conducir una interpretación política de ARISTÓTELES en términos puramente naturalistas. Marsilio DE PADUA acentuaba la idea del carácter natural del orden social, de su absoluta necesidad y del primado del bien común sobre el individual. Como era de esperar, dicha interpretación favorecía la independencia del orden humano respecto del espiritual. De este modo, la teoría aristotélica de la autosuficiencia de la ciudad, a la luz de la

entre el rey de Francia y el clero, limitaba las prerrogativas del papa y reafirmaba la idea de la supremacía de los concilios frente al papado. En su primer artículo, declaraba la supremacía de los concilios generales sobre el papado y limitaba los poderes del papa. De este modo, la Iglesia de Francia adquirió una gran autonomía respecto de Roma y el rey se aseguró la lealtad del clero francés.

${ }_{15}$ Que el elemento predominante en la teoría política de Marsilio DE PADUA sea el aristotelismo político no significa que no tuviera también una eclesiología. Al respecto, $c f r$. J. A. CASTELLO DuBRA, «La eclesiología de Marsilio DE PADUA», en Bulletin du centre d'études médiévales d'Auxerre, Hors-série, núm. 7, 2013, bttp:// cem.revues.org/12781. Sobre fuentes en general del pensamiento político de Marsilio DE PADUA, cfr. R. SCHOLZ, «Marsilius von Padua und die Genesis des modernes Staatsbewusstseins», en Historische Zeitsschrift, 156 (1937), 88-103; A. GEWIRTH, Marsilius of Padua. The Defensor Pacis, I: «Marsilius of Padua and the Medieval Political Philosophy», London, McMillan, 1951. También J. Quillet, La Philosophie politique de Marsile de Padoue, Paris, Vrin, 1970. Para una valoración de conjunto del Defensor pacis, cfr. B. BAYONA, «El poder y el Papa. Aproximación a la filosofía política de Marsilio DE PADUA», en Isegoría. Revista de Filosofía Moral y Política, 36 (2007), 197-218. También L. MARTínEZ GÓMEZ, «Estudio preliminar», en Marsilio DE PADUA, El defensor de la paz, Madrid, Tecnos, 2009, xv-xliv. 
nueva interpretación, abría perspectivas desconocidas hasta entonces por los juristas a la soberanía de la comunidad política.

En Guillermo DE OCKHAM, el otro teórico al flanco de Luis de Baviera en la disputa con Juan XXII, sobresalen fundamentalmente una eclesiología y una política dependientes de los presupuestos de una metafísica nominalista y una ética voluntarista. La principal obra de OCKHAM suscitada por esta polémica era Ocho cuestiones sobre el poder del papa ${ }^{16}$. OCKHAM critica acerbamente algunos aspectos característicos de la Iglesia medieval, como son la bierocracia totalitaria y la clericalización de la Iglesia.

En referencia al primer aspecto piensa OСКНАM que oponer el poder espiritual al poder temporal es una sutileza sin sentido, semejante a las que gustan de realizar los metafísicos, como igualmente lo es contraponer la naturaleza a la gracia y la política de los intereses temporales a la economía de la salvación. Todas estas realidades no son más que expresión de una única fuente: Dios creador y conservador de todos los seres. ¿Por qué, pues, distribuir arbitrariamente en géneros distintos las manifestaciones de la actividad humana que no se distinguen por ninguna diferencia fundamental? Conocemos bien con qué minucia ha mostrado OCKHAM, siguiendo el principio de economía del pensamiento, la inutilidad de las distinciones que los filósofos se han complacido en establecer en sus sistemas. Por ello, la distinción entre lo espiritual y lo temporal no es admisible, tanto menos si se utiliza para aplicarla a los poderes civil y eclesiástico de una misma comunidad política. ¿Por qué el poder del rey no puede ser considerado espiritual, al menos en algunas ocasiones? La atribución de poderes religiosos al poder civil y la protesta dirigida contra los canonistas, que han prohibido a los príncipes toda intervención en el campo espiritual, son la lógica consecuencia de la supresión de la distinción entre lo temporal y espiritual llevada a cabo por Guillermo DE OCKHAM ${ }^{17}$.

Por otro lado, la eclesiología de OCKHAM no admite en la Iglesia más estructuras que las que se derivan de la Escritura. OСКНАM critica la excesiva clericalización de la Iglesia. La Iglesia no es el clero, ni el episcopado, ni el colegio de cardenales, ni el papa, sino el conjunto de los cristianos. En una palabra, en coherencia con su eclesiología y su filosofía, la Iglesia es el conjunto de individuos cuya propiedad común es compartir la misma fe. A partir de ahí, hace pasar a un segundo plano todo lo que en la Iglesia es institucional o transciende a la realidad de los individuos cristianos. Además, una comunidad no deja de ser la misma porque se la considere desde un punto de vista religioso (la Iglesia) o político (el Estado). Es la misma comunidad, vista bien como sociedad que participa de una misma fe, bien como sociedad organizada en el plano civil. La Iglesia es así asimilada al Estado cristiano. Estado e Iglesia, en virtud de una filosofía que rechaza las distinciones metafísicas, han de identificarse. En consecuencia,

16 G. DE OcKHAM, «Octo quaestiones de potestate Papae», en H. S. OfFler, Guillelmi de Ockham Opera Politica, I, Manchester, Manchester University Press, 1974, 6-217. Cfr. también G. DE OCKHAM, «De imperatorum et pontificum potestate», en H. S. OfFleR, Guillelmi de Ockham Opera Politica, IV, Oxford, Oxford University Press, 1997, 261-355 (trad. esp. Sobre el poder de los emperadores y los papas, Madrid, Marcial Pons, 2007, con «Estudio preliminar» de J. C. UTRERA); G. DE OCKHAM, «Breviloquium de principatu tyrannico», en H. S. OfFler, Guillelmi de Ockham Opera Politica, IV, 79-260 (trad. esp. Sobre el gobierno tiránico del Papa, Madrid, Tecnos, 1992).

17 Las consecuencias últimas de dicha supresión las sacará Thomas HoBBES, para quien el soberano cristiano es simultáneamente cabeza de la Iglesia y del Estado, que son una y la misma cosa: el Estado cristiano, cuya exposición se realiza en el tercer libro del Leviathan. 
las autoridades laicas son invitadas a ejercer la potestad que, tanto en el plano civil como en el religioso, un clero ambicioso ha pretendido arrebatarle ${ }^{18}$. He aquí un inequívoco rasgo del nacimiento del espíritu laico ${ }^{19}$.

\subsection{El conciliarismo y la exigencia democratizadora en la Iglesia}

Finalmente, se ha aludido en varias ocasiones al conciliarismo, pero no se ha determinado aún qué es. El conciliarismo es una doctrina eclesiológica sobre la naturaleza de la potestad eclesiástica, según la cual la autoridad suprema de la Iglesia no reside en el papa, sino en el concilio o asamblea universal de los cristianos, que agrupa no solo a los eclesiásticos, sino también a los laicos, e incluso a la naciones tomadas como sujetos de derecho. En tal sentido, como hace tiempo observó FIGGIS, el movimiento conciliarista es la culminación del constitucionalismo medieval en el ámbito eclesiástico ${ }^{20}$. De otro lado es importante advertir que el conciliarismo guarda innegables vínculos con la corriente intelectual dominante en el siglo XIV: el nominalismo ${ }^{21}$.

Los orígenes del conciliarismo parecen encontrarse en dos fuentes de la Edad Media. La primera fuente es de naturaleza filosófica, y consiste en una corriente que postula la democratización de la Iglesia, amparándose para ello en la doctrina de Aristóteles según la cual el origen del poder público radica en la comunidad, de la que el príncipe recibe inmediatamente su potestad. En este sentido, la doctrina de Marsilio DE PADUA es un exponente claro del conciliarismo, dado que aplica esta doctrina al régimen de gobierno de la Iglesia. En opinión de Marsilio, recibiendo el papa su poder del conjunto de los fieles (como ocurre en el caso del gobernante secular), y solo remotamente de Dios, se entiende que la potestad papal debe estar sujeta al concilio universal (que representa a toda la Iglesia), como el rey lo está al parlamento. La segunda fuente es de naturaleza teológica. Se trata de la doctrina medieval del papa hereje. En el contexto de

18 Cfr. G. DE LAGARDE, La naissance de l'esprit lä̈que, V, 1963, 280.

19 A propósito de Guillermo DE OCKHAm y Marsilio DE PADUA, M. HARDT y A. NEGRi han realizado una sugerente interpretación de la obra de dichos pensadores en el contexto de la transición tardomedieval a la filosofía política moderna no tanto como las figuras más representativas del nominalismo y averroísmo latino, que son las coordenadas interpretativas clásicas en las que se suele encuadrar a estos pensadores, sino como representantes cualificados del «acontecimiento principal de la modernidad: la afirmación de los poderes de este mundo, el descubrimiento del plano de la inmanencia». Al respecto, $c f r$. M. HARDT y A. NEGRI, Imperio, Barcelona, Paidós, 2016, 91.

${ }^{20}$ Cfr. J. N. Figgis, From Gerson to Grotius (1414-1625), Cambridge, Cambridge University Press, 1907, 35. De esta obra reviste una peculiar importancia el capítulo segundo, «The Conciliar Movement and the papalist reaction», 35-61. Además de esta obra, sobre el conciliarismo desde una perspectiva predominantemente politica, cfr. B. TIERnEY, Foundations of the Conciliar Theory: The Contribution of the Medieval Canonists from Gratian to the Great Schism, Cambridge, Cambridge University Press, 1955; F. OAKLEY, The Conciliarist Tradition: Constitutionalism in the Catholic Church 1300-1870, Oxford, Oxford University Press, 2004.

${ }_{21} \mathrm{Cfr}$. J. VERGER, «Le transfert de modèles d'organisation de l'Église à l'État à la fin du Moyen Age», en J. Ph. Genet y B. Vincent, Etat et Eglise dans la genèse de l'État moderne, 31-39. Este autor ha expresado con claridad encomiable la relación histórica cierta que se da entre conciliarismo y nominalismo. En su opinión, «el conciliarismo, lejos de designar solamente una doctrina y unas prácticas eclesiásticas precisas, representa una suerte de estado de espíritu largamente extendido [...] entre las personas letradas de una concepción nominalista de la sociedad y del mundo, que, constatando la universalidad de la crisis y la urgencia de la reforma en todos los sentidos de la palabra [...] concluye que el remedio reside en el recurso a asambleas y consejos en los que, frente a los detentadores desviados de la autoridad, pueda expresarse la voluntad general [de todos los cristianos]» (38). Trad. propia. 
Aviñón, OcKHAM dio particular relevancia a esta teoría. Era opinión que se remontaba al Decreto de Graciano que un papa podía ser depuesto en caso de herejía por un concilio general. Pero si el papa podía ser depuesto por un concilio era inevitable admitir que la autoridad del concilio es superior al papa. Guillermo DE NOGARET había apelado a la doctrina del papa hereje en sus ataques a Bonifacio VIII y en idéntica doctrina amparaba Guillermo DE OCKHAM las acusaciones lanzadas contra Juan XXII.

\section{LA SOBERANÍA POLÍTICA EN EL DE POTESTATE CIVILI DE FRANCISCO DE VITORIA}

\subsection{Las relecciones de Vitoria}

Las relecciones (relectiones) constituyen la obra principal de Francisco DE VITORIA. A ellas debe este autor en gran parte su celebridad. En la Universidad de Salamanca se llamaban relecciones (o repeticiones) a unas conferencias revestidas de especial solemnidad pronunciadas por los graduandos o los catedráticos ante sus respectivas facultades o ante la Universidad. Se trataba de una reminiscencia de las famosas disputas medievales, las quaestiones disputatae y las quaestiones quodlibetales. Las constituciones de la Universidad de Salamanca, otorgadas por el papa Martín V en 1422, sancionaban esta práctica e imponían a los catedráticos la obligación de impartir una relección cada año, por primavera, que correspondiese de algún modo a la materia expuesta ese curso 22 .

Se conservan también algunas relecciones impresas de otros autores, como Pedro DE Osma, Domingo de Soto, Melchor CAno, Domingo BÁÑEz, etc. Pero con nadie alcanzó este género científico-literario la altura y brillantez que tuvo en Francisco DE VITORIA, que supo presentar bajo este género cuestiones vivas y originales que por su importancia y actualidad atrajeron poderosamente la atención del público universitario de su tiempo. En opinión de URDÁNOZ, «VITORIA ha pasado a la historia como el verdadero y propio autor de las relecciones teológicas, el único de nuestros autores clásicos que se ha inmortalizado con la publicación de estas sus solemnes lecciones universitarias, la obra científico-literaria cumbre de su vida» ${ }^{23}$.

Bastará echar una rápida ojeada a algunas temáticas tratadas por la relecciones de VITORIA para comprender el interés que despertaron en su tiempo: la potestad soberana del Estado, la potestad espiritual de la Iglesia, la potestad del papa y del concilio en la Iglesia, la legitimidad de la intervención de la Corona española en América, las cuestiones relativas al derecho de guerra, la cuestión del divorcio de Enrique VIII, el interés renacentista por la magia, etc. El conjunto de las relecciones de VITORIA, cronológicamente presentado, es el siguiente: De potestate civili (1528), De homicidio (1530), De matrimonio (1531), De potestae Ecclesiae prior (1532), De potestate Ecclesiae posterior (1533), De potestate Papae et concilii (1534), De augmento caritatis (1535), De eo ad quod tenetur veniens ad usum rationis (1535), De simonia (1536), De temperantia (1537), De indis prior (1539), De indis posterior seu de iure belli (1539), De

\footnotetext{
${ }^{22}$ Cfr. T. URDÁNOZ, «Introducción biográfica», en Obras de Francisco de Vitoria, 78.

23 T. URDÁNOZ, «Introducción biográfica», 82.
} 
magia $(1540)^{24}$. Pero desde la primera edición de las mismas (la edición de Boyer, Lyon 1557) ${ }^{25}$, todos sus editores las presentaron siguiendo un orden lógico, agrupando unas temáticas tan dispares, que correspondían a la actividad académica de VITORIA, según criterios de unidad lógica.

\subsection{La relección De potestate civili}

El De potestate civili es la primera relección escrita por VITORIA. Fue compuesta en su segundo año de docencia en la Universidad de Salamanca, cuya cátedra de teología le fue asignada en 1526. Fue pronunciada en la Navidad de 1528 y contiene la materia impartida en el curso de 1527-1528.

Vitoria había concebido el plan de estudiar conjuntamente las cuestiones, de tanta actualidad en sus días, de la potestad civil y eclesiástica. Prueba de ello son las referencias cruzadas entre el De potestate civili y el De potestate Ecclesiae prior. En tal sentido el De potestate civili se refiere al De potestate Ecclesiae prior en lo relativo a la subordinación del fin temporal al espiritual ${ }^{26}$, del mismo modo que el De potestate Ecclesiae prior da por sentada la noción de potestad civil tal como se trata en el De potestate civili ${ }^{27}$. Se puede por ello decir que el De potestate civili constituye la base de la serie de relecciones dedicadas a la cuestión de la potestad. En el momento mismo del nacimiento y consolidación del Estado moderno, dado el tipo de relaciones que este establece con la Iglesia, la oportunidad de la temática no podía ser mayor ${ }^{28}$.

Por otro lado, el De potestate civili es no solo una de las mejores y más conocidas relecciones de VITORIA, sino que en ella se exponen, además de las ideas fundamentales del gran renovador salmantino sobre el poder político y el Estado, algunas nociones importantes sobre la sociedad internacional [la «república de todo el orbe» (totus orbis, qui aliquo modo est una respublica), resultante de las recíprocas relaciones jurídicas entabladas en su seno por los diversos Estados] y el derecho de gentes (es decir, el derecho internacional). En efecto, según VITORIA, el derecho internacional, que regula las relaciones entre Estados, obliga a estos no solo en virtud de pactos y convenciones suscritos, sino en virtud de la misma «autoridad de todo el orbe» (totius orbis auctoritate). En este sentido afirma VITORIA en la parte conclusiva del De potestate civili: «De todo lo dicho se infiere un corolario: que el derecho de gentes no solo tiene fuerza por el pacto y convenio de los hombres, sino que tiene verdadera fuerza de ley. Y es que el orbe todo, que en cierta manera forma una república, tiene la potestad de emanar leyes justas y a

24 El orden cronológico ha sido establecido por Beltrán DE HeREDIA. Cfr. V. BELTRÁn DE HeREDIA, Los manuscritos del maestro Francisco de Vitoria OP, Madrid-Valencia, Biblioteca de tomistas españoles, IV, 1928, 132-153.

25 Reverendi Patris F. Francisci de Victoria ordinis Praedicatorum Sacrae Theologiae in Salmanticensi Academia quondam primarii Professoris Relectiones theologicae XII in duos tomos divisae, Lugduni, apud Iacobum Boyerium, 1557.

${ }^{26}$ Cfr. F. DE Vitoria, De potestate civili, n. 14. La cursiva es del propio Vitoria. Las citas de las diversas relecciones de VITORIA las tomamos siempre de la edición de T. URDÁNOZ, Obras de Francisco de Vitoria, Madrid, BAC, 1960.

27 Cfr. F. DE VitORIA, De potestate Ecclesiae prior, q. 1, n. 8; q. 3, n. 2.

28 Para una visión de conjunto del pensamiento político de Francisco DE VITORIA, $c f r$. J. CORDERO PANDO (ed.), Francisco de Vitoria, Relectio de potestate civili. Estudios sobre su filosofía politica, Madrid, CSIC, 2008. 
todos convenientes, como son las del derecho de gentes [...] y ninguna nación puede darse por no obligada ante el derecho de gentes, porque está dado por la autoridad de todo el orbe» ${ }^{29}$. Es clara, pues, la analogía que VITORIA establece entre Estado y sociedad internacional, de manera que lo que es la potestad civil del Estado frente a los súbditos, es la autoridad de todo el orbe frente a los Estados que integran la sociedad internacional, bien sabido que solo en virtud del ius naturale la autoridad de todo el orbe es capaz de obligar a los Estados en cuestión. En tal sentido, según C. GARCÍA PASCUAL, la inescindible relación en VITORIA entre ius naturale e ius gentium confiere una universalidad al derecho internacional de VITORIA de la que carece el pensamiento de $\mathrm{GROTIO}^{30}$. De este modo, queda bien establecida la estrecha relación que une el $D e$ potestate civili y las dos relecciones de ámbito internacional, el De indis prior y el $D e$ indis posterior seu de iure belli. Por todo ello FERRAJOLI ha podido decir que «Francisco DE VITORIA, cuyo papel preeminente en la fundación del derecho internacional es actualmente admitido por toda la crítica historiográfica, es autor de extraordinaria modernidad, en muchos aspectos más avanzado que muchos de sus sucesores, incluido Grotio» ${ }^{31}$, siendo sus dos grandes méritos al respecto, de nuevo con FERRAJOLI, el haber puesto los fundamentos tanto del Derecho internacional (en la elaboración de los títulos legítimos de conquista) como de la concepción moderna del Estado como sujeto soberano ${ }^{32}$.

En lo referente al contenido, la materia de esta relección se agrupa en dos grandes cuestiones: a) el origen y la naturaleza de la potestad o poder civil, y b) la obligación en conciencia del cumplimiento de las leyes que emanan de dicha potestad. Para facilitar su lectura ViTORIA introduce un sumario que divide la obra en veinticuatro números y un sucinto proemio en el que se enuncia la tesis general de la obra, como después veremos.

\subsection{Algunas fuentes del De potestate civili}

Como teólogo dominico, VITORIA encuentra su primera fuente de inspiración en la obra de Tomás DE AQUINO, ante todo en la Summa theologiae, especialmente en la I-II ${ }^{\text {ae }}$, q. 96, titulada De potestate legis humanae, en cuyos arts. 4-6 se plantea el Aquinate, exactamente como hará VITORIA en la segunda parte del De postestate civili, si la ley humana se impone ante el foro de la conciencia (a. 4), si todos los hombres le están sometidos (a. 5) y si a los que están bajo su jurisdicción les está permitido actuar más allá de las palabras de la ley (a. 6). De todas estas cuestiones trata, en efecto, la segunda parte del De potestate civili (nn. 14-24).

29 F. DE Vitoria, De potestate civili, n. 21, in fine. La cursiva es del propio Vitoria.

30 Cfr. C. GarCía PASCuAl, Norma mundi: la lucha por el derecho internacional, Madrid, Trotta, 2015, 22-23. De modo semejante opina A. PÉREZ LuÑo, según el cual el dominico español aboga por un derecho común de la humanidad, cuyos principios alcancen validez universal al reconocer como sujetos del mismo a los Estados y a los individuos (cfr. A. PÉREZ LuÑo, La polémica sobre el Nuevo Mundo. Los clásicos españoles de la filosofía del derecho, Madrid, Trotta, 1992, 78).

31 L. FERRAJOLI, «L'America, la conquista, il diritto. L’idea di sovranità nel mondo moderno», en Meridiana, 15 (1992) 21. Trad. propia.

32 Cfr. ibid., 22. 
Pero, además de a la teología moral de Tomás DE AQUino, las relecciones de VITORIA sobre la potestad (civil, eclesiástica y del papa y del concilio) deben no poco a la literatura teológica y canónica de los siglos XIV y XV, especialmente francesa, que había estudiado tanto el conciliarismo como las disputas sostenidas por príncipes y papas a lo largo del siglo XIV. El conciliarismo requería discernir la naturaleza y límites del poder del papa frente al concilio. Era una cuestión intraeclesiástica. Las disputas entre príncipes y papas exigían, por su parte, clarificar los límites entre la potestad eclesiástica y la estatal, así como explicar previamente en qué consistía la naturaleza espiritual y temporal, respectivamente, de ambas potestades, que OCKHAM y sus seguidores habían discutido. Como puede verse, se trata de buena parte de las cuestiones que dan nacimiento a la filosofía política moderna.

Debido a su larga estancia en la Universidad de París, VITORIA estaba bien informado sobre todo ello. En ningún lugar como en Francia urgía tanto clarificar las cuestiones del conciliarismo y de las relaciones del Estado con la Iglesia. No es casual, por ello, que en marzo de 1512 se celebrara un acto solemne en la Universidad de París en el que el maestro Luis BER comparaba las dos potestades, eclesiástica y civil, y el profesor del Colegio de Monteagudo, Jacobo Almain, intervenía exponiendo la doctrina conciliarista y la idea democrática aplicada a la potestad de la Iglesia a partir de la teoría de la transmisión del poder civil, que reside en la comunidad, a los príncipes. Es más que probable que VITORIA asistiera a aquella sesión académica ${ }^{33}$.

No está de más decir que así como los grandes teólogos del conciliarismo del siglo XV habían sido Pedro D’AILLY y Juan GERSON, sus defensores a inicios del siglo XVI habían sido precisamente Juan MAIR y Jacobo Almain, ambos maestros de ViTORIA. Esos cuatro nombres forman lo que ha sido llamado la cuadriga del conciliarismo galicano $^{34}$. El influjo de los dos últimos sobre VITORIA es considerable. BELTRÁN DE HEREDIA, por su parte, asegura que VITORIA debe a ALMAIN muchos elementos de sus relecciones ${ }^{35}$.

El discurso de ALMAIN en el referido acto académico de 1512 dio origen posteriormente a tres escritos: una Quaestio resumptiva agitata in Vesperiis de dominio naturali, civili et ecclesiastico (que contiene un análisis del origen y transmisión del poder civil como fundamento de las cuestiones posteriores sobre el poder del papa y del concilio general); el Tractatus de auctoritate Ecclesiae et Conciliorum generalium, escrito posteriormente por encargo de la Universidad de París, en polémica con el cardenal Cayetano; y, finalmente, una última obra sobre estas cuestiones, titulada Expositio circa decisiones M. Guillermi de Occam de potestate ecclesiastica et laica. Es manifiesto que una fuente de primera relevancia de la teología conciliarista de ALMAIN es OCKHAM, cuya obra Octo quaestiones de potestate Summi Pontificis analiza y estudia pormenorizadamente. Como puede verse, estas tres obras de ALMAIN contienen en su integridad

33 Cfr. T. URDÁNOZ, «Introducción biográfica», 111-112.

34 Cfr. R. García Villoslada, La Universidad de París durante los estudios de Francisco de Vitoria OP (1507-1522), 165.

35 Cfr. V. Beltrán de Heredia, Comentarios a la Secunda secundae, III-IV (De iustitia), Salamanca, Introducción, 1934, xxx. Cfr. también R. GaRcía VillosladA, La Universidad de París durante los estudios de Francisco de Vitoria OP (1507-1522), caps. VI y VII, sobre Juan MAIR y Jacobo ALMAIN. Cfr. también R. GARCÍA VILlosLADA, «Jacobo Almain y Francisco de Vitoria», en Estudios eclesiásticos, 59 (1936), 311-325. 
la temática que VITORIA desarrollará, aunque no del mismo modo, en la serie de sus relecciones sobre la potestad civil, eclesiástica y del papa y el concilio. Así pues, es ajustado a la realidad decir que después de Tomás DE AQUINO, Jacobo ALMAIN representa una de las primeras fuentes del pensamiento de VITORIA sobre la potestad civil y eclesiástica.

Aunque en el De potestate civili VITORIA no informa sobre los autores en que se ha inspirado para su elaboración, se hace eco al menos de la vastedad de la literatura al respecto ${ }^{36}$. En cualquier caso, en esta relección se percibe claramente que VITORIA sigue paso a paso la marcha de las ideas de los citados opúsculos de Almain, de quien, según URDÁNOZ, toma muchos elementos doctrinales y documentales para su concepción del poder político ${ }^{37}$.

\subsection{El contenido y las nociones fundamentales del De potestate civili}

Como se ha dicho ya, el De potestate civili estudia dos grandes cuestiones: el origen y naturaleza del poder público (nn. 1-14) y la obligatoriedad moral de las leyes (nn. 1524). En el proemio comienza VITORIA centrando su teoría del poder político en el marco más amplio de una teoría del Estado (o de la república, como lo llama inspirándose en el Derecho romano). Ya desde el comienzo se caracteriza la potestad política como el poder para el gobierno de la república. En efecto, se trata de aquel «poder público por el que se gobiernan los Estados» ${ }^{38}$. Se diferencia así este poder de otras formas de poder cuyo estudio no afronta ahora VITORIA. En cuanto pública, esta potestad se diferencia de la potestad privada, a la que se refiere VITORIA en el último número de esta relección (donde estudia la obligación de los mandatos impuestos en virtud de potestad privada por el padre a los hijos y el marido a la mujer) ${ }^{39}$. En cuanto temporal o civil, se diferencia también de la potestad eclesiástica, cuyo estudio reserva VITORIA a las futuras relecciones eclesiásticas. Así pues, el De potestate civili acota como objeto de sus consideraciones el estudio de la potestad pública secular y civil.

Pues bien, la tesis general que se sostiene a lo largo de toda esta relección es que no hay poder, o lo que es igual, no hay potestad pública secular y civil que no derive de Dios. Dice, en efecto, VitORIA: «El texto que se ha de releer y tratar es el que toma el Maestro de las Sentencias en 2 d. 44 de San Pablo en su epístola a los Romanos: No hay poder que no emane de Dios» ${ }^{40}$. En otros términos, el poder público, secular y civil es de origen divino. Ganada esta idea en el proemio, se reitera posteriormente en el n. 1 de nuestra relección: «Todo poder público [...] por el cual se administra la república secular, no solo es justo y legítimo, sino que tiene a Dios por autor, de tal suerte que ni por el consentimiento de todo el mundo se puede suprimir» ${ }^{41}$.

36 Cfr. F. DE VitORIA, De potestate civili, proemio.

37 Cfr. T. URDÁNOZ, «Introducción biográfica», 112.

38 F. DE VITORIA, De potestate civili, proemio: «de potestate publica [...] qua respublicae gubernantur».

39 Cfr. F. DE VITORIA, De potestate civili, n. 24.

40 F. DE Vitoria, De potestate civili, proemio. El «Maestro de las Sentencias» referido aquí por VitoRIA es Pedro Lombardo, autor del Liber sententiarum, una obra comentada por multitud de autores tanto de la primera como de la segunda escolástica.

41 F. DE VitORIA, De potestate civili, n. 1. 
Siendo el hecho a analizar la potestad pública, secular y civil, su estudio científico prescribe el análisis etiológico del mismo a partir de las diversas causas que concurren en su constitución, que según el método escolástico (que VITORIA hace plenamente suyo) son cuatro. En este sentido ViTORIA analiza el hecho de la potestad pública y secular desde la múltiple perspectiva de la causalidad final, eficiente (autor), material (sujeto) y formal (naturaleza).

\subsubsection{El fin de la potestad civil}

Resulta curioso que en una obra de teoría moral y política como el De potestate civili las primeras citas sean tomadas de la Metafísica y de la Física de ARISTÓTELES, en lugar de la Ética o de la Política del Estagirita ${ }^{42}$. Se puede ver en ello una prevención frente al nominalismo predominante en la Universidad de París, donde recibió su formación inicial ${ }^{43}$. Según los nominalistas, el mundo de las criaturas naturales, careciendo de suficiente densidad y estabilidad ontológicas, no es capaz de garantizar desde el punto de vista lógico las afirmaciones necesarias y, en consecuencia, propiamente científicas. En opinión de VITORIA, en cambio, las cosas, incluidas también las entidades políticas como son la sociedad y el Estado, poseen una esencia que las orienta establemente hacia un fin y que las dota de un cierto grado de necesidad ${ }^{44}$.

Tras esta justificación, más metafísica que política, del fin en general, procede VITORIA a aplicar la noción de fin al poder político ${ }^{45}$. VITORIA hace suyo a este propósito el razonamiento sobre la naturaleza humana que en nuestros días se ha dado en llamar antropología biológica. Dice nuestro autor así: «Conviene pensar que así como el hombre sobrepasa a los animales por la razón, por la sabiduría y por la palabra, así a este eterno, inmortal y sabio animal muchas cosas le fueron negadas por la providencia que fueron atribuidas y concedidas a los restantes animales» ${ }^{46}$. A diferencia de los demás animales, a los que la providencia dotó de los medios necesarios para su supervivencia, «al hombre, concediéndole la razón y la virtud, dejo frágil, débil, pobre, enfermo, destituido de todos los auxilios, indigente, desnudo e implume, como arrojado de un naufragio» ${ }^{47}$. De manera que para subvenir a la multitud de necesidades que hacen $\tan$

42 Cfr. ibid., n. 2.

43 Cfr. J. A. Maravall, «I pensatori spagnoli del "secolo d'oro"», en L. FiRPo (a cura di), Storia delle idee politiche, economiche e sociali, Torino, Utet, 1989, 611-693, 654. Sobre el trasfondo nominalista al que Vitoria pretende responder, $c f r$. R. GARCía VillosladA, La Universidad de París durante los estudios de Francisco de Vitoria OP (1507-1522), 128; A. DE LA HERA, «El magisterio de Vitoria en el contexto universitario de su época», en Estudios de historia social y económica de América, 13 (1996), 547-562, 550; K. MiCHALSKI, Les courants philosophiques à Oxford et à Paris pendant le XIV siècle, Cracovie, Imprimerie de l'Université, 1921, y también del mismo autor Les sources du criticisme et du scepticisme dans la philosophie du XIVe siècle, Cracovie, Imprimerie de l'Université, 1924. Sobre la relación entre nominalismo y la nueva física de la Universidad de París, cfr. P. DuHem, Etudes sur Leonard da Vinci, III, Paris, A. Hermann, 1911, 263-583: «Dominique Soto et la Scolastique parisienne». fine».

${ }_{44}$ Cfr. F. DE VitoRIA, De potestate Ecclesiae, I, q. 3,a. 3, n. 8: «Necessitas et ratio rerum sumenda est ex

${ }^{45}$ Cfr. F. DE Vitoria, De potestate civili, n. 3.

46 Ibid. Las cursivas son mías.

47 Ibid., n. 4. A propósito de la antropología biológica, cfr. L. PRIETO LÓPEZ, El hombre y el animal: nuevas fronteras de la antropología, Madrid, BAC, 2008, 533-543. 
onerosa la vida humana, «fue necesario que los hombres no anduviesen vagos y errantes $[\ldots]$ sino que viviesen en sociedad $[\ldots]$ y se ayudasen mutuamente» ${ }^{48}$.

De otro lado, la sociedad satisface no solo las necesidades naturales del hombre, sino también, y sobre todo, las espirituales. En efecto, «la palabra es nuncio del entendimiento» ${ }^{49}$, por medio del cual se eleva el hombre por encima de los animales. Pero el hombre la tendría inútilmente si viviera en soledad ${ }^{50}$. Además, la voluntad, cuyo ornamento es la justicia, «quedaría deforme y defectuosa, alejada del consorcio humano» ${ }^{51}$. En breve, «el hombre es naturalmente civil y social» ${ }^{52}$, como igualmente naturales son las ciudades y repúblicas, dice VITORIA, que nacieron con el fin de la defensa de la vida humana y la satisfacción de sus necesidades, tanto físicas como espirituales. Ahora bien, el fin de las ciudades es el mismo que el del poder público, «porque si para la guarda de los mortales son necesarias las congregaciones y asociaciones de hombres, ninguna sociedad puede persistir sin alguna fuerza y potestad que gobierne y provea» ${ }^{53}$. VITORIA llama a tal fin la utilidad, o incluso la comodidad, de los hombres ${ }^{54}$.

$\mathrm{Si}$, por un lado, la concepción de VITORIA de la sociedad puede decirse natural, en el sentido de que, como sociedad perfecta, es independiente y autónoma de la Iglesia (en virtud de sus propios fines de naturaleza temporal), su insistencia, por otro lado, en que el fin tanto de la sociedad como de la potestad pública es la utilidad (o comodidad) de los hombres, nos indica que el pensamiento del teólogo burgalés está dando pasos decididos hacia una discreta secularización de la vida política. En efecto, si la comunidad política, dada su esencia y fines peculiares, pertenece al orden natural, y el poder político se le ha dado para su conservación, se sigue de ahí que tal poder es legítimo con independencia de consideraciones de carácter espiritual; y que, por tanto, el poder que ejercitan los príncipes infieles, como es el caso de los indios americanos, es legítimo. El Estado, que desciende del derecho natural y no de ratificación espiritual alguna, es legítimo a condición de conformarse con el orden de la naturaleza ${ }^{55}$.

\subsubsection{El autor de la potestad civil}

El poder público viene de Dios, ha sentado ViTORia en la tesis general. Esto es tanto como decir que Dios es el autor o artífice del poder político, pues como creador del hombre, ha puesto en su naturaleza la necesidad de asociarse en comunidad y esta necesita el poder político para su gobierno. Dice, en efecto, VitORIA: «Habiendo mostrado que la potestad pública está constituida por derecho natural, y teniendo el derecho natural a Dios por su autor, es manifiesto que el poder público viene de Dios» ${ }^{56}$, porque «si las repúblicas y las sociedades están constituidas por derecho divi-

\footnotetext{
${ }^{48}$ F. DE Vitoria, De potestate civili, n. 4.

49 Ibid.

${ }^{50}$ Cfr. ibid.

51 Ibid.

52 Ibid.

53 Ibid., n. 5

${ }^{54}$ Cfr. ibid. Cfr. también De matrimonio.

$55 C f r$. F. DE VITORIA, De indis prior, en general.

56 F. DE Vitoria, De potestate civili, n. 6.
} 
no o natural, con el mismo derecho lo están las potestades, sin las cuales las repúblicas no pueden subsistir» ${ }^{57}$.

Ahora bien, para evitar malentendidos es necesario aclarar que el poder es de origen divino solo en un sentido general, es decir, en cuanto que pertenece naturalmente a la sociedad, y en tal sentido con independencia de la voluntad humana, por cuanto es indispensable para el gobierno, del que ninguna sociedad puede carecer. Sin embargo, la forma del poder político en que se concreta la necesaria acción de gobierno depende por completo de la voluntad de los hombres. En breve, el poder público procede de Dios en el sentido de tener en Él su origen, pero la forma de su ejercicio es de origen humano. No es, pues, en virtud del derecho natural y divino, sino solo en virtud del derecho bumano (es decir, del pacto de los hombres) como puede poseer un hombre cualquiera título legítimo para el gobierno de la nación. Veremos, enseguida, cómo VITORIA tropieza, o eso al menos creemos, en este aspecto.

De manera que la institución genérica de la potestad pública, sin la que la sociedad es inviable, procede del derecho natural y es de origen divino, mientras que la determinación particular de la modalidad de ejercicio de dicha potestad y de la forma de gobierno corresponde a la libre determinación humana.

\subsubsection{El sujeto de la potestad civil}

Por sujeto de la potestad civil debe entenderse no tanto quien ejerce dicha potestad, sino aquel a quien pertenece o en quien reside antes de cualquier determinación positiva. Pues bien, según ViTORIA, el sujeto de la potestad civil es la misma república. Con expresión propia de la escuela dice: «La causa material [es decir, el sujeto] en la que dicho poder reside es por derecho natural y divino la misma república» ${ }^{58}$. A ella compete «gobernarse a sí misma, administrar y dirigir al bien común todos sus poderes» ${ }^{59}$. Así pues, el sujeto último y principal de la potestad pública es la misma comunidad política. VITORIA razona al respecto certeramente: «Como por derecho natural y divino hay un poder de gobernar la república y, quitado el derecho positivo y humano, no haya razón especial para que aquel poder esté más en uno que en otro, es menester que la misma sociedad se baste a sí misma y tenga poder de gobernarse» ${ }^{60}$. Así pues, la potestad pública reside originalmente en la sociedad.

Ahora bien, no pudiendo la potestad pública ser ejercitada por una multitud de hombres, «fue necesario que la administración se confiase a alguno o algunos que llevasen este cuidado y nada importa que se encomendase a uno o a varios» ${ }^{61}$. La idea es clara: la delegación de la potestad pública es imprescindible para el gobierno. Esta delegación, a su vez, puede realizarse a favor de una persona (el rey o príncipe) o de varias (la aristocracia o la democracia), según las formas de gobierno establecidas por ARISTÓTELES. Luego la constitución concreta de la forma del Estado no es determinada

\footnotetext{
57 Ibid.

58 Ibid., n. 7.

59 Ibid.

60 Ibid.

61 Ibid., n. 8.
} 
por la naturaleza, sino por la voluntad de los hombres. Por tanto, solo en virtud de un pacto o acuerdo se realiza la delegación del poder y nadie podrá alegar ser titular de la potestad pública por derecho divino ${ }^{62}$.

Sin embargo, algo más adelante afirma VITORIA en sentido contrario: «Parece, pues, que la potestad regia no viene de la república, sino del mismo Dios, como sienten los doctores católicos» ${ }^{63}$. Como es natural, la mayor parte de los comentaristas ven en este texto una inconsecuencia con lo anteriormente sentado por VITORIA. Es, pues, necesario reconocer que cuando VITORIA intenta determinar en concreto cuál es el sujeto del poder político no se expresa claramente. Por un lado afirma que la comunidad política, en quien reside originalmente el poder, lo delega o encomienda al príncipe; pero por otro lado afirma que este no lo recibe de la república, sino de Dios mismo. Es necesario estudiar esta cuestión más detenidamente.

De un lado, la idea de la delegación o encomienda del poder político está claramente expuesta en varios pasos del De potestate civili. Afirma, por ejemplo, nuestro autor que «puesto que esta potestad está principalmente en los reyes, a los cuales la república encomendó sus veces, debe disputarse del principado regio y potestad» ${ }^{64}$. Ello supone, aceptada la tesis general sobre el origen divino del poder, que Dios entrega a la comunidad el poder de gobernarse a sí misma y que esta, por la necesidad de administrar la república, lo delega a su vez al gobernante. En efecto, «teniendo la república poder sobre todos los grupos de ella y no pudiendo ser ejercitado este poder por la misma multitud [...], fue necesario que la administración se confiase a alguno o algunos que llevasen este cuidado, y nada importa que se encomendase a uno o a varios» ${ }^{65}$. Pero, de otro lado, la idea contraria del inmediato origen divino del poder político aparece en varias ocasiones. En efecto, al inicio del n. 8 dice VitORia: «La monarquía o regia potestad no solo es legítima y justa, sino que los reyes, por derecho divino y natural, tienen el poder y no lo reciben de la misma república ni absolutamente de los hombres» ${ }^{66}$. En el mismo sentido, algo más adelante en el mismo n. 8, vuelve a insistir VITORIA: «Parece, pues, que la potestad regia viene no de la república, sino del mismo Dios, como sienten los doctores católicos» ${ }^{67}$, por lo que «la sagrada Escritura [...] llama a los príncipes ministros de Dios y no de la república» ${ }^{68}$. De nuevo, finalmente: «Parece, pues, que están en un error aquellos que defienden que el poder de la república es de derecho divino, mas no el poder del rey» ${ }^{69}$.

62 Cfr. ibid., nn. 8 y 14.

63 Ibid., n. 8.

${ }^{64}$ Ibid., n. 7.

65 Ibid., n. 8. Esto mismo afirma ViTORIA, y de manera más contundente si cabe, en el Comentario de la Secunda secundae. En él se sienta inequívocamente que la potestad del príncipe depende de la república. En efecto, «los magistrados civiles, los gobernadores y los príncipes tienen solo aquella autoridad y poder que les concede la comunidad. De ello se sigue el siguiente corolario: que los súbditos están obligados a obedecer a los superiores en aquellas cosas para las que la nación ha concedido a ellos el poder y en la forma en que esta lo ha establecido. Por ello, si la nación elige al rey a condición de que exija solamente determinados tributos e impuestos y este exige otros, los súbditos no están en modo alguno obligados a obedecerlo, ya que todo su poder depende de la comunidad» (cit. por E. NASZALYI, El estado según Francisco de Vitoria, Madrid, Ediciones Cultura Hispánica, 1948, 241).

66 F. DE VitORIA, De potestate civili, n. 8.

67 Ibid.

68 Ibid. Las cursivas son mías.

69 Ibid. 
Ha habido diversos intentos para salvar esta ambigüedad —así la llama URDÁNOZ— en el pensamiento de VITORIA ${ }^{70}$. Este autor, por ejemplo, cree que VITORIA quiere expresar solo que el poder político viene de Dios no solamente en abstracto, sino en todos los príncipes y poseedores legítimos del mismo, «pues es de derecho natural no solo que exista la autoridad civil en la república, sino también que esta potestad sea comunicada a alguno o algunos gobernantes» ${ }^{71}$. NASZALYI, por su parte, tras reconocer la existencia de esta ambigüedad, intenta explicar la mente de VITORIA sobre este asunto afirmando que, según VITORIA, aunque la traslación de la potestad se realiza cuando la comunidad designa a la persona en quien delega el ejercicio de la potestad, con esta designación y delegación la comunidad política no crea la potestad pública, sino que solo la concede a quien elige. Por tanto, la potestad viene de Dios, de él procede la potestad del Estado, que aquí se transfiere y la comunidad política solamente designa la persona ${ }^{72}$. MARAVALL, finalmente, en un nuevo intento de clarificar la cuestión del sujeto propio del poder político, afirma que según VITORIA «la república transfiere al príncipe su autoridad, es decir, según nuestra interpretación, su capacidad de mandar legítimamente, pero la sustancia o el contenido de esta función, es decir, el mando, la potestad, la asume el príncipe en el momento en que le es conferida la autoridad; y esta potestad es la misma que Dios, a través de la naturaleza, ha transmitido a la comunidad» ${ }^{73}$. Para esta interpretación MARAVALL se apoya, fundamentalmente, en el paso del De potestate civili n. 8 en el que VITORIA distingue la potestad (de origen divino) y la autoridad (de origen humano), según el cual la comunidad política autoriza el ejercicio de la potestad. Dice, en efecto, VITORIA: «Porque aunque el rey sea constituido por la misma república (ya que ella crea al rey), no transfiere al rey la potestad, sino la propia autoridad» ${ }^{74}$.

Ahora bien, más allá de la ambigüedad o contradicción de VITORIA, cuesta trabajo pensar que un autor de su talla no haya podido expresar su pensamiento al respecto con la debida precisión. La claridad con la que un siglo después SuÁREZ determina inequívocamente el origen humano de las formas del poder político, nos hace pensar que la ambivalencia de VITORIA sobre el origen del poder político puede deberse a una cierta justificación del absolutismo de su tiempo. En efecto, SUÁREZ afirma claramente en el De legibus: «Formalmente considerado, aunque este poder de gobierno procede sin duda de Dios, su transmisión a una persona concreta resulta de la concesión del propio pueblo, y en tal sentido es de derecho humano [...] Luego, hablando sencillamente, el poder proviene de los hombres» ${ }^{75}$. MARAVALL apunta a un posible deslizamiento de ViTORIA hacia las tesis del absolutismo $^{76}$. En efecto, VITORIA se estaría

70 Cfr. T. URDÁNOZ, «Introducción biográfica», 119. TRUYOL, en cambio, prefiere llamarla una contradicción. Cfr. A. Truyol SerRA, Los principios de Derecho público en Francisco de Vitoria, Madrid, Cultura Hispánica, 1946, 43-44.

71 T. URDÁNOZ, «Introducción biográfica», 120.

72 Cfr. E. Naszalyi, El Estado según Francisco de Vitoria, 241.

73 J. A. MARAVALL, «I pensatori spagnoli del "secolo d'oro"», 656. Trad. propia.

74 F. DE Vitoria, De potestate civili, n. 8.

75 F. SuÁREZ, De legibus, 3,4,5.

76 Sostienen esta idea S. Lisarrague, P. Mesnard, C. Barcia, A. Dempf, etc. Cfr. S. Lissarrague, La teoría del poder en Francisco de Vitoria, Madrid, Instituto de Estudios Políticos, 1947, 78 y ss. En sentido contrario, T. URDÁNOZ, «Introducción biográfica», 141. Cfr. también H. BEUVE-MERY, La théorie des pouvoirs publics d'après F. de Vitoria, Paris, Spes, 1928; A. TRuYOL SERRA, Los principios de Derecho público en Francisco de Vitoria, Madrid, Cultura Hispánica, 1946, 43-44, quien, para salvar la aparente contradicción, insiste en que «ViTORIA quiere destacar que el rey no es un simple mandatario de la república [...] sino un órgano de la 
convirtiendo en un defensor del absolutismo, como un siglo después lo juzga el jesuita RODRIGO DE ARRIAGA ${ }^{77}$. Con todo, la cuestión no es suficientemente clara ni se puede dar por cerrada.

Proponemos, por ello, dos textos de ViTORIA, tomados del Comentario de la Summa theologiae de sentido contrario, para poner de manifiesto esta ambigüedad. El primero se expresa en un sentido contrario a la tesis absolutista, afirmando que la potestad del príncipe depende en todo de la república. En efecto, «los magistrados civiles, los gobernadores y los príncipes tienen solo aquella autoridad y poder que les concede la comunidad. De ello se sigue el siguiente corolario: que los súbditos están obligados a obedecer a los superiores en aquellas cosas para las que la nación ha concedido a ellos el poder y en la forma en que esta lo ha establecido. Por ello, si la nación elige al rey a condición de que exija solamente determinados tributos e impuestos y este exige otros, los súbditos no están en modo alguno obligados a obedecerlo, ya que todo su poder depende de la comunidad» ${ }^{78}$. En cambio, en sentido favorable a la tesis absolutista se expresa VITORIA cuando afirma que la delegación de la potestad al monarca, a diferencia de la que se realiza en el régimen democrático y aristocrático (en la que la potestad se concede con limitaciones y con la posibilidad de revocarla), es realizada sin condiciones y a perpetuidad, de modo que no puede ser retirada, si fue concedida en estas condiciones. En concreto, «la república, una vez concedido el poder al rey, no puede reivindicarlo después si lo concedió al rey y sus herederos sin condiciones y perpetuamente» (respublica dedit auctoritatem regi, quam non potest repetere, si sine conditione dedit in perpetuum illi et eius successoribus ${ }^{79}$. El uso de la fórmula condicional no deja de tener un sentido retórico, pues ¿de qué otro modo sino incondicional y perpetuamente se entregaba la potestad al rey en el siglo Xvi? Sorprende, por otro lado, la semejanza de la fórmula de VITORIA con las palabras de BODIN, que vamos a ver al final de este artículo.

VITORIA es un autor del siglo XVI, la época en que España evolucionaba de las formas políticas medievales a la constitución del Estado monárquico moderno. Su época es la de los Reyes Católicos y de Carlos V. La supremacía, la majestad encarnada por el nuevo Estado moderno y su soberano era un hecho y las teorías políticas, como dice Jellinek, tienden de ordinario a plegarse y justificar los hechos ${ }^{80}$. Quizás a este estado de cosas se deban las vacilaciones de VITORIA en la determinación del sujeto del poder político. En cualquier caso la idea de que la delegación del poder es irrevocable, incondicional, perpetua, y en tal sentido dinástica, tal como lo expresan las palabras de la cuestión 105 del Comentario de la II-II ${ }^{a e}$ de VITORIA que acabamos de ver, parece una concesión de Vitoria al absolutismo.

La idea vitoriana de soberanía es bastante próxima a la de Bodin. Ahora bien, como vamos a ver enseguida, conviene tener presente que en BoDin la soberanía es la característica fundamental del poder político de la monarquía absolutista.

república, el cual, una vez constituido como tal, no puede ser revocado su poder mientras lo ejerza a favor del bien común» (44).

77 Cfr. J. A. MARAVALL, «I pensatori spagnoli del "secolo d'oro"», 656.

${ }^{78}$ F. DE Vitoria, Comentario de la II-IIae, cit. por E. NASZALYI, El Estado según Francisco de Vitoria, 241.

79 F. DE Vitoria, Comentario a la I-IIae, q. 105, a. 2, ed. BeltrÁn DE Heredia, t. 6, Salamanca, 1952, 482.

${ }^{80}$ Cfr. G. JellineK, Allgemeine Staatslehre, Berlin, Verlag von O. Häring, 1914, 452. 


\subsubsection{La naturaleza de la potestad civil}

Recapitulemos. Ya sabemos que, según VITORIA, el poder político es de origen divino. Procede inmediatamente de la naturaleza humana, de la que Dios es autor. Los hombres, en efecto, no pueden vivir más que socialmente. Pero ninguna sociedad humana puede subsistir sin una potestad que la gobierne. Por eso la potestad es esencial a la comunidad política, que es su sujeto titular último. Pero aún no hemos definido qué es la potestad política. Es, pues, el momento de preguntarnos qué es o en qué consiste formalmente la potestad.

VITORIA cree necesario distinguir entre poder (potentia) y potestad (potestas). El poder es una fuerza, una energía, una capacidad de obrar. Pero la potestad es un tipo de poder que añade algunas propiedades nuevas. En efecto, «la potestad, además de la potencia para la operación, comprende una cierta preeminencia y autoridad» ${ }^{81}$. Así pues, además del poder, la potestad conlleva la superioridad o preeminencia (o soberanía) y el carácter ético. No es mera fuerza coercitiva, según VITORIA. Se puede decir, por tanto, que la potestad pública representa en VITORIA un poder supremo de naturaleza moral de obligar a los hombres. Precisamente en virtud de su carácter moral, las leyes emanadas de dicha potestad obligan en conciencia, como afirma la segunda parte del De potestate civili. Esto supuesto, VITORIA define la potestad pública como «la facultad, autoridad o derecho de gobernar la sociedad civil» ${ }^{82}$. De donde se sigue que la potestad pública es un poder supremo de naturaleza moral cuyo fin es el gobierno del Estado.

Por otro lado, como sabemos, la potestad del Estado es temporal o civil, no espiritual. Es, por su propia esencia, independiente del orden espiritual o de la gracia, por lo cual, correspondiendo a la naturaleza humana, se da de igual modo entre paganos que cristianos. De ahí que tanto los Estados de los paganos como las autoridades que los gobiernan están revestidos de una potestad igualmente legítima. Por ello, en cuanto dotado de potestad temporal, el Estado es independiente de la Iglesia. En otras palabras, en lo tocante a asuntos temporales o civiles no tiene obligación alguna de obedecer a la Iglesia ${ }^{83}$. Además, la potestad del Estado es, por definición, pública. Mira al bien común, que es el que compete al Estado. El carácter público de la potestad del Estado se manifiesta ante todo en la potestad de legislar ${ }^{84}$. Pues bien, en el ámbito público y temporal o civil la potestad de la república es suprema (o soberana). VITORIA no acepta, sin embargo, que esta potestad sea suprema en el sentido de eximir al rey del respeto y obediencia de las leyes por él mismo dictadas. En este sentido, no acepta el carácter de legibus solutus del rey, que no pocos legistas y juristas de la corte, inspirándose en el derecho imperial romano, venían reivindicando, como veremos que hace BODIN $^{85}$.

81 F. DE ViTORIA, De potestate Ecclesiae, q. 1, n. 2: «Videtur potestas praeter potentiam ad actionem dicere preeminentiam quandam et auctoritatem».

82 F. DE VITORIA, De potestate civili, n. 10: «Potestas publica est facultas, auctoritas, sive ius gubernandi rempublicam civilem».

83 Cfr. F. DE VITORIA, De potestate Ecclesiae, I.

${ }^{84}$ Cfr. F. DE Vitoria, Comentario a la I-IIae, q. 90, a. 3.

85 En efecto, en el De potestate civili, n. 21, se expresa VITORIA abiertamente contra esta condición del soberano como absuelto de la ley. 
La supremacía de esta potestad se sigue de que el Estado es una comunidad política perfecta, que no carece de nada, y en tal sentido no puede tener potestad alguna por encima de ella ${ }^{86}$. Conviene aclarar que la idea de comunidad perfecta es una noción jurídica, no moral ${ }^{87}$. En efecto, el Estado de los indios, aunque no ha alcanzado la perfección ética, es, sin embargo, una sociedad perfecta. En tal sentido, una sociedad es perfecta cuando posee supremacía interior e independencia exterior. Ambas propiedades son las dos caras de la soberanía política. La potestad política es suma, o lo que es lo mismo, puede gobernar todos sus asuntos con autoridad y poder propios. Esta supremacía interior de la potestad política se da, ante todo, según VITORIA, en la potestad de legislar, que conlleva también, además de la capacidad administrativa, la potestad punitiva ${ }^{88}$. A su vez, la potestad es independiente, porque el Estado, a cuyo gobierno sirve, es una unidad autónoma o independiente de cualquier otro Estado. Dicha independencia exterior capacita al Estado a proceder contra los enemigos externos, juzgándolos y castigándolos si son particulares o declarándoles la guerra sin son Estados ${ }^{89}$.

Es claro que la idea de soberanía no podía hacerse explícita más que cuando el Estado moderno se desligó o independizó de otras entidades políticas. En efecto, como ya sabemos, en las luchas ocurridas al final de la Edad Media por la independencia del Estado, las monarquías nacionales son las portadoras de la idea del Estado moderno. Por eso, las monarquías modernas nacen bajo el signo laico y nacional de la lucha con el papa y el emperador, respectivamente, y es a ellas a quien se atribuye el poder soberano ${ }^{90}$. En este sentido también VITORIA establece y separa al Estado naciente tanto de la Iglesia (y de la potestad eclesiástica) como del imperio. Ya conocemos la afirmación de ViTORIA respecto de la superioridad (o soberanía) del Estado sobre la Iglesia en lo concerniente a asuntos civiles. Respecto del emperador afirma rotundamente «que no es señor de todo el orbe» ${ }^{91}$. Nunca se ha demostrado, afirma, ni por derecho divino ni natural ni humano, que el emperador tenga este dominio sobre todo el mundo ${ }^{92}$.

\subsection{Excursus sobre la soberanía en Bodin}

Este trabajo trata sobre la soberanía política en VITORIA. Pero la idea de soberanía tiene en BoDIN su madurez y su forma canónica. Por ello es necesario dedicar unas líneas a la soberanía en este autor, que la expone sistemáticamente por primera vez en la obra Los seis libros de la República (1576), casi cincuenta años después del De potestate civili de VITORIA. El propósito de BODIN, además de elaborar una ciencia política

${ }^{86}$ Cfr. F. DE Vitoria, De Indis, II, n. 7, a propósito de la comunidad perfecta.

87 Cfr. E. Naszalyi, El Estado según Francisco de Vitoria, 139.

s8 Cfr. F. DE Vitoria, De matrimonio, II, n. 1.

89 Cfr. F. DE ViTORIA, Comentario a la II-IIae, q. 40, a. 1.

90 Cfr. G. JelLineK, Allgemeine Staatslebre, 456: «In den mittelalterlichen Kämpfen um die Unabhängigkeit des Staates und seiner Gewalt ist es überall die Monarchie, welche als Träger des Staatsgedankens auftritt. Daher erscheint dem politischen Denken der Kampf um den Staat wesentlich als Kampf des weltlichen Herrschers mit dem Papste, des Königs mit dem Kaiser [...] Es ist daber fast selbstverständlich, daß die Souveränität zuvörderst auf den Monarchen bezogen wird». Las redondas son mías.

91 F. DE Vitoria, De Indis, I.

92 Cfr. F. DE VitORIA, De potestate Ecclesiae, I. 
moderna que sustituya la vieja Política de ARISTÓTELes, es elaborar un concepto de poder político suficientemente fuerte para poner al Estado a salvo de las turbulencias internas del momento (sobre todo, político-religiosas), así como de las guerras frente a otros Estados.

De otro lado, Bodin representa la conclusión y síntesis del proceso de imperialización de la figura del príncipe, de quien la soberanía (sowveraineté) es un atributo esencial. Profesor de Derecho romano en la Universidad de Toulouse y abogado de la corte, la figura de Jean BoDIN (1530-1596) se inscribe plenamente en la tradición de los juristas y publicistas en los que se apoyan las monarquías modernas para rodear de prestigio intelectual el impulso ascendente que está experimentando el Estado en los albores de la Época Moderna y para legitimar sus pretensiones absolutistas. No es necesario por evidente insistir en la semejanza de BODIN con los legistas de la corte de Felipe el Hermoso, de los que ya hemos hablado.

El Estado (o República, como lo llama Bodin, al igual que VitORIA) dispone de una potestad suprema y perpetua para su gobierno. En efecto, «la república es el recto gobierno de varias familias, y de lo que les es común, con poder perpetuo y supremo» ${ }^{93}$. Como dicho poder no ha sido definido todavía por ningún filósofo ni jurisconsulto, dice BoDiN ${ }^{94}$, es necesario determinar en qué consiste. Así pues, «la soberanía es el poder absoluto y perpetuo de una República, que los latinos llaman majestad ${ }^{95}$. El carácter absoluto del poder consiste en ser otorgado simplemente, sin condiciones ni límites para su ejercicio, fuera de los que impone la ley de Dios y la ley natural ${ }^{96}$. A su vez, la perpetuidad de dicho poder implica que, una vez otorgado, se ejerce en nombre propio «en el modo y por el tiempo que le [al soberano] plazca (tant et si longuement qu'il lui plaira) ${ }^{97}$. De las propiedades de absoluto y perpetuo se sigue que el soberano puede dictar y derogar leyes con completa libertad. En tal sentido, dice BoDin, es habitual incluir en la conclusión de las leyes y decretos la fórmula car tel est notre bon plaisir $^{98}$. Por otro lado, aunque las leyes no deben chocar con razones morales, «no dependen más que de la sola y pura voluntad del soberano» ${ }^{99}$. La soberanía, pues, se expresa, ante todo, en la potestad de promulgar leyes, de cuya obediencia, según BoDIN, el propio príncipe está absuelto.

En cualquier caso, el fundamento de la relación entre soberanía y absolutismo presente en el pensamiento de BoDIN estriba más en el carácter perpetuo del poder que en el de absoluto, pues en virtud de la perpetuidad el soberano ejerce el poder en nombre propio, no como concedido o delegado por la comunidad, en el modo y por el tiempo que desee. ¿No es quizás esta misma lógica de ideas la razón de las vacilaciones de VITORIA en la cuestión del sujeto de la potestad política a propósito del absolutismo? ¿Es simple casualidad que, como hemos visto, VITORIA emplee exactamente los mismos términos que BoDIN, a saber, incondicional, perpetuo e irrevocable, para referirse al poder

93 J. Bodin, Les six livres de la République, I, 1.

${ }_{94}$ Cfr. ibid., I, 8.

95 Ibid: «La souveraineté est la puissance absolue et perpétuelle d'une République, que les Latins appellent majestatem».

${ }_{96}$ Cfr. J. Bodin, Les six livres de la République, I, 8.

97 Ibid.

98 Ibid.

99 Ibid. 
soberano? ${ }^{100}$ ¿No es quizás esta la clave de solución de la ambigüedad de VITORIA en la determinación del sujeto del poder político?

\section{A MODO DE CONCLUSIÓN}

Aunque la idea de soberanía está presente en el De potestate civili solo de un modo implícito, contiene ya todos los elementos de la definición de soberanía de Los seis libros de la República de BODIN. Sin embargo, el hecho de que VITORIA rechace la condición de legibus solutus del principe, a diferencia de aquel, y dedique la segunda parte del De potestate civili a estudiar la obligatoriedad moral de cumplir en conciencia las leyes, pone en el pensamiento del pensador dominico una nota de bumanismo ético que, en el caso de que se admita la antes mencionada tendencia absolutista en su teoría del Estado y del poder político, circunscribe y matiza dicha propensión.

VITORIA fue llamado el Sócrates cristiano. No fue, en efecto, un metafísico. Orientó su filosofía hacia los argumentos morales y jurídicos, subordinando el interés especulativo a las grandes cuestiones candentes que los nuevos tiempos estaban planteando. Entre dichas cuestiones dedicó especial atención a las relacionadas con el nacimiento del Estado moderno, a saber: la naturaleza del poder soberano del Estado (tanto en sí mismo como en su relación con la Iglesia) y la índole de las fuentes del derecho internacional, que regula la relación entre los diversos Estados, cuyo conjunto, como sociedad de Estados, constituye la respublica totius orbis. De esta respublica afirma vigorosamente, con el mismo espíritu humanista y ético, «habet [...] potestatem ferendi leges aequas et convenientes omnibus, quales sunt in iure gentium» ${ }^{101}$.

100 Cfr. supra, nota 79.

101 F. DE VITORIA, De potestate civili, n. 21, in fine: «Tiene la potestad de emanar leyes justas y convenientes a todos, como son las del derecho de gentes». Las cursivas son mías. Cfr. supra, notas 30 y 32 . 